at King's College Hospital is similar. Five cases of cancer, four in an early stage 1, were found by the clinical examination of the breasts of 654 women in a London practice. Screening by the cervical smear test is still one of the most worth-while forms of early diagnosis, for two reasons: firstly, lesions that are truly early or even precancerous can be detected, and, secondly, unlike the bladder, the whole of the affected tissue can be removed without serious consequences. A report from the Exeter Clinic of the Family Planning Association indicates no excess of abnormal nuclei or malignant appearances in the cells of the cervix in women taking oral contraceptives in comparison with women wearing an intra-uterine contraceptive device.

Many of the experimental studies concern chemical agents that are not present in the normal human environment. Of the few that could lead to knowledge of how to prevent human cancer one may mention the attempts of R. A. M. Case to find safer alternatives to carcinogenic aromatic amines in certain routine laboratory tests-for example, the use of benzidine for the detection of blood in stools. An effort by C. E. Searle to remove carcinogenic chemicals of the same and other types from school laboratories in the City of Birmingham is surely one that should be matched in every education department in the country. Though cancer of the colon is one of the commoner forms of neoplasia in both men and women, and some attention is being paid to its earlier diagnosis and treatment, ${ }^{4}$ the only study directly aimed at discovering its causes is that of R. E. O. Williams at St. Mary's Hospital. He reports that the faeces of English people living on mixed diets contain more anaerobic Bacteroides, fewer enterococci and anaerobic Sarcinae, and significantly more neutral and acid steroids than the faeces of Ugandans living on a mainly vegetable diet and enjoying a lower risk of developing bowel cancer.

There seems to be rather a paucity of virological research. And why are so few studies concerned with the commonest type of cancer in men-namely, cancer of the bronchus? Nevertheless, the latest report gives plenty of evidence of imaginative work-indeed, perhaps more than in previous years.

\section{Fair Inquiry}

Some two and a half years ago the Monopolies Commission, on the instruction of the President of the Board of Trade, turned its attention to restrictive practices in the professions. Whether a body accustomed to investigate and pass judgement on trade practices is equally well equipped to examine the affairs of the professions remains to be seen. But certainly professional conduct, some of it stemming from traditional ethical principles, is legitimately a subject of public concern. Indeed its main purpose is to protect the public from abuse.

The medical profession is merely one of a number that are now objects of the commission's scrutiny, for it would seem that the nature of what professions characteristically offer in their services is being examined rather than the specific practices of each profession in turn, though these must be

British Medical fournal, 1967, 1, 376.

British Medical fournal, 1967, 4, 496.

British Medical fournal Supplement, 1968, 2, 42.

' British Medical fournal Supplement, 1968, 2, 38. looked at if generally valid inferences are to be drawn about their relevance to the public interest. At least this would seem to follow from the wide terms of reference guiding the commission and the variety of professions from which it is obtaining evidence in the course of this particular inquiry. However that may be, a report from the commission based on inadequate evidence or an incomplete understanding of the reasons for some professional procedure could be damaging to the reputation of any one of the professions as well as to the protection the public has through that procedure. Nor would such confusion enhance the commission's own reputation for fair and impartial inquiry in the public interest. Yet in refusing to follow its customary procedure and declining to hear oral evidence, despite a formal request from some of the professional organizations to do so, the commission is running a risk of reaching conclusions that may be unjust or at best irrelevant.

The commission's inquiry is into practices that are restrictive of entry into a profession, fees charged, rendering of services by persons in partnership, the manner in which services are supplied, the carrying on of another business, and advertising. ${ }^{1}$ In other words, it can look into and form conclusions on most aspects of professional life, and an initial restriction on the commission itself that it should not report on practices expressly authorized by any enactment or royal charter was largely removed some months after the inquiry began. ${ }^{2}$ Both the General Medical Council ${ }^{3}$ and the British Medical Association ${ }^{4}$ have submitted written evidence to the commission, as have professional bodies representing (among others) dentists, engineers, barristers, and surveyors.

Concerned as it has for so long been to protect the public from quacks and unscrupulous practitioners, the medical profession described in its evidence such " restrictive practices" as examinations to gain entry to the profession; ethical prohibitions on a variety of practices, such as advertising; and the rules that should guide a doctor to satisfy himself that a patient who comes to him for treatment is not already in the care of another doctor. These and the many other traditional features of professional life that have an element of restriction in them are perfectly fit subjects for inquiry, but the misinterpretation to which they are often seen to be liable is evidence enough that they need proper explanation to people who may be unfamiliar with their purpose-namely, to prevent unqualified or dishonest people from deceiving the public. It would be unfortunate if such an influential body as the Monopolies Commission was to reach conclusions without hearing the full evidence on exceedingly complex issues and thus run the risk of harming the delicate personal relationships between doctors and their patients.

\section{Delivery after Caesarean Section}

An estimated 254,540 caesarean sections were performed in England and Wales in the ten-year period 1957-66. ${ }^{1}$ The number of deaths " associated with but not necessarily due to caesarean section " investigated in the Confidential Enquiry into Maternal Deaths during the same period was 488 , giving a mortality rate of about $0 \cdot 2 \%$, approximately ten times the maternal mortality for all deliveries.

E. Holland ${ }^{2}$ recorded a $4 \%$ incidence of scar rupture and a $4 \%$ maternal mortality in subsequent pregnancy after 
caesarean section. Moreover, the ratio of successful vaginal delivery to rupture was only $4 \cdot 3$ to 1 . The same author ${ }^{3}$ analysed the subsequent obstetric history of 3,372 patients for whom section had been performed for "contracted pelvis," and again there was a $4.1 \%$ mortality. It ranged from $1.4 \%$ with elective section to $26.5 \%$ after failed attempts at vaginal delivery. These figures gave apparent support to the view originating in America that "once a caesarean always a caesarean.” But C. M. Marshall and L. W. Cox reported a series of 5,583 patients with contracted pelvis for which section was performed, who in a subsequent pregnancy had a mortality of $0.5 \%$ and a perinatal mortality of 16.8 per 1,000 . Moreover, there were no deaths in 348 who were in labour less than seven hours. The lower segment operation had been performed in $75 \%$.

These analyses were comparable in that both dealt with caesarean section for alleged cephalo-pelvic disproportion and contracted pelvis, indications which, if confirmed, would be associated with a maximum incidence of repeated operation. Sir John Peel ${ }^{5}$ analysed from the records of 13 teaching hospitals 3,429 deliveries after caesarean sections. The incidence of rupture in 1949 was $1.8 \%$ and in $19641.1 \%$, but in those patients who were successfully delivered vaginally it was $0.7 \%$. Uterine rupture was the most serious complication of attempted vaginal delivery after caesarean section despite the fact that the attempt was successful in $85 \%-91 \%$ of cases. An important observation was that, as the percentage rose of those who were allowed to undergo labour after caesarean section for disproportion, so the incidence of successful vaginal delivery fell and the perinatal mortality rose. At King's College Hospital when $47 \%$ were allowed a trial of labour the perinatal mortality was 71 per 1,000 , but when only $33 \%$ were the mortality fell to 16 per 1,000 . These figures emphasize the need for careful assessment of the case during the antenatal period.

Cephalo-pelvic disproportion is more important than contracted pelvis, and accurate diagnosis can be difficult, as emphasized by J. A. McGarry. ${ }^{6}$ In prolonged labour with impaired uterine efficiency, particularly in a primigravida, there are often several unfavourable factors, such as large foetus, high head, poor flexion, and premature rupture of membranes. Caesarean section with an incorrect diagnosis of disproportion, even supported by $x$-ray pelvimetry, may be followed by vaginal delivery of a larger infant. In the group with contracted pelvis, disproportion, prolonged labour, or failed surgical induction, McGarry reported that $90(57 \%)$ of 158 patients had vaginal delivery, though 12 had elective repeat section for severely contracted pelvis.

When the indication for section was a non-recurring factor such as antepartum haemorrhage or foetal distress, $124(82 \%)$ of 152 patients were delivered vaginally. As the incidence

1 Report on Confidential Enquiry into Maternal Deaths in England and Wales, 1964-66, 1969 . London, H.M.S.O.

2 Holland, E., Proceedings of the Royal Society of Medicine, Section of Obstetrics and Gynaecology, 1920, 14, 22.

- Holland, E., fournal of Obstetrics and Gynaecology of the British Empire, 1921, 28, 358.

- Marshall, C. M., and Cox, L. W., in Transactions of the 12th British Congress of Obstetrics and Gynaecology, 1949, p. 30 . London, Austral Press.

- Peel, J., Fournal of Obstetrics and Gynaecology of the British Commonwealth, 1968, 75, 1282.

- McGarry, J. A., Fournal of Obstetrics and Gynaecology of the British Commonwealth, 1969, 76, 137.

- Dewhurst, C. J., fournal of Obstetrics and Gynaecology of the British Empire, 1957, 64, 113.

- Notelovitz, M., and Crichton, D., South African Medical fournal, 1967, 41,323 . of vaginal delivery in the whole series of 415 patients was $58 \%, 242$ mothers were saved an unnecessary operation.

Seven perinatal deaths associated with vaginal delivery included two intrauterine deaths before labour and two neonatal deaths due to congenital heart disease-an excellent corrected mortality of 12 per 1,000 total births. One stillbirth, due to scar dehiscence in labour, is a reminder that this is a danger. ${ }^{5} 78$ Caudal or epidural analgesia conceals the pain of a rupturing scar, and unless foetal distress is detected early and dealt with effectively intrauterine death may be the first indication of rupture. But caudal or epidural analgesia can be a decisive factor in making vaginal delivery possible by relieving distress and promoting normal uterine activity.

McGarry considers the use of oxytocin justifiable but stresses the need for vigilant supervision. He advocates 2 units in $500 \mathrm{ml}$. of glucose saline at 30 drops a minute, increasing to 5 units if necessary. But previous caesarean section is not an indication for induction, and the prognosis for vaginal delivery is improved when labour begins spontaneously. Because of weak or fibrous scars and sometimes tears extending laterally to involve large vessels, repeat section should not be entrusted to unsupervised junior staff.

Caesarean section has contributed much to the safety of both mother and baby in modern obstetrics, but the indications for it, and the difficulties and dangers associated with it, should be kept under constant review. The advice of Smellie is as wise today as it was two hundred years ago: "We ought never to trust too much or be over-sanguine in respect to any particular method of practice but vary the same as we feel it necessary."

\section{Money for Charity}

By a happy decision of the Conference of Representatives of Local Medical Committees ${ }^{1}$ general medical practitioner charities will receive a windfall of $£ 800,000$. This was money set aside from the pay of N.H.S. general practitioners from 1952 to 1959 to promote a fund to provide interest-free group-practice loans. The work of the group-practice loans scheme was superseded in 1966 by the General Practice Finance Corporation and by the introduction of special payments to general practitioners working in recognized groups.

Last year the Conference asked ${ }^{2}$ that the $£ 800,000$ should be returned on a proportional basis to those who had contributed to it or to their dependants in the case of those who had died. Apparently the amount per head would average about $£ 40$, less tax. The Health Department stated that the task of tracing the proper recipients, or their heirs, and in working out what should be credited to them in each of eight separate years would be so enormous as to be impracticable. The Conference this year considered other proposals for distributing the money, but it will be generally agreed that the substantial majority of representatives who voted in favour of its going to charity were not only being generous but also setting an example in a year which the B.M.A. had designated as medical charities year.

\footnotetext{
1 British Medical fournal Supplement, 1969, 2, 144.

- British Medical fournal Supplement, 1968, 2, 189.
} 